\title{
Coordination between proteasome impairment and caspase activation leading to TAU pathology: neuroprotection by cAMP
}

\author{
MJ Metcalfe ${ }^{1}, Q$ Huang ${ }^{1}$ and ME Figueiredo-Pereira ${ }^{\star, 1}$
}

Neurofibrillary tangles (NFTs) are hallmarks of Alzheimer's disease (AD). The main component of NFTs is TAU, a highly soluble microtubule-associated protein. However, when TAU is cleaved at Asp421 by caspases it becomes prone to aggregation leading to NFTs. What triggers caspase activation resulting in TAU cleavage remains unclear. We investigated in rat cortical neurons a potential coordination between proteasome impairment and caspase activation. We demonstrate that upon proteasome inhibition, the early accumulation of detergent-soluble ubiquitinated (SUb) proteins paves the way to caspase activation and TAU pathology. This occurs with two drugs that inhibit the proteasome by different means: the product of inflammation prostaglandin J2 (PGJ2) and epoxomicin. Our results pinpoint a critical early event, that is, the buildup of SUb proteins that contributes to caspase activation, TAU cleavage, TAU/Ub-protein aggregation and neuronal death. Furthermore, to our knowledge, we are the first to demonstrate that elevating cAMP in neurons with dibutyryl-cAMP (db-cAMP) or the lipophilic peptide PACAP27 prevents/ diminishes caspase activation, TAU cleavage and neuronal death induced by PGJ2, as long as these PGJ2-induced changes are moderate. db-cAMP also stimulated proteasomes, and mitigated proteasome inhibition induced by PGJ2. We propose that targeting CAMP/PKA to boost proteasome activity in a sustainable manner could offer an effective approach to avoid early accumulation of SUb proteins and later caspase activation, and TAU cleavage, possibly preventing/delaying AD neurodegeneration.

Cell Death and Disease (2012) 3, e326; doi:10.1038/cddis.2012.70; published online 21 June 2012

Subject Category: Neuroscience

Alzheimer's disease (AD) is an age-related neurodegenerative disorder. Little is known about the initial pathology, and when symptoms are detected, neurodegeneration is so advanced that it is seldom reversible. Neurofibrillary tangles (NFTs) are pathological hallmarks of AD. The major component of NFTs is TAU, a microtubule-associated protein that is abundant in neurons and highly soluble; yet TAU aggregates abnormally in AD. ${ }^{1}$ Truncation of TAU at Asp421 ( $\left.\triangle T A U\right)$ by caspases is an early event in $A D$ tangle pathology. ${ }^{2-4}$ In addition, $\triangle T A U$ is detected in NFTs, indicating that the apoptotic cascade is involved in NFT formation. ${ }^{5}$

The initial events leading to caspase activation and $\Delta T A U$ are poorly defined. We propose that proteasome impairment could be one of the initial critical events that contributes and leads to caspase activation concurring with $\triangle T A U$, protein aggregation and neuronal death. There is a general agreement that proteasome impairment is involved in the pathogenesis of AD. Defective proteasome activity is connected to the early phase of $A D$ characterized by synaptic dysfunction, as well as to late $A D$ stages linked to accumulation and aggregation of ubiquitinated $(\mathrm{Ub})$ proteins in both senile plaques and NFTs. ${ }^{6,7}$

To investigate a potential coordination between proteasome impairment and caspase activation leading to TAU pathology, we treated rat cerebral cortical neurons with two drugs that inhibit the proteasome by different means: prostaglandin J2 (PGJ2) and epoxomicin. PGJ2 is an endogenous product of inflammation that inhibits the proteasome by inducing oxidation of its subunit S6 ATPase (Rpt5), ${ }^{8}$ and/or by promoting dissociation of the $26 \mathrm{~S}$ proteasomes. ${ }^{9}$ By promoting $26 S$ proteasome disassembly, PGJ2 resembles the effects of agents that induce oxidative stress. ${ }^{10} \mathrm{We}$ recently demonstrated in rat cortical neurons that PGJ2 induces accumulation of Ub proteins, caspase activation, $\triangle T A U$ and its aggregation, as well as neuritic dystrophy. ${ }^{11}$ Epoxomicin is a specific and irreversible inhibitor of the proteasome that forms a covalent adduct with the amino terminal Thr of the $20 \mathrm{~S}$ proteasome catalytic subunits, generating irreversible morpholino adducts. ${ }^{12}$ Other proteasome inhibitors, that is, MG132 and lactacystin, were shown

\footnotetext{
${ }^{1}$ Department of Biological Sciences, Hunter College and Graduate Center, City University of New York, New York, NY, USA

${ }^{*}$ Corresponding author: M Figueiredo-Pereira, Department of Biological Sciences, Hunter College and Graduate Center, City University of New York, 695 Park Avenue, Room 827N, New York, NY 10065, USA. Tel: +212 650 3565; Fax: +212 772 5227; E-mail: pereira@ genectr.hunter.cuny.edu Keywords: proteasome; caspase; TAU; cAMP; neuroprotection; Alzheimer

Abbreviations: $\triangle$ TAU, TAU cleaved at Asp421; AD, Alzheimer's disease; db-cAMP, dibutyryl-cAMP; DMSO, dimethyl sulfoxide; ECL, enhanced chemiluminescence; Ep, epitope; Epac, exchange protein directly activated by cAMP; MTT, 3-(4,5-dimethylthiazol-2-yl)-2,5-diphenyl tetrazolium bromide; PACAP27, pituitary adenylate cyclase-activating polypeptide-27; PBS, phosphate buffered saline; PGD2, prostaglandin D2; PGJ2, prostaglandin J2; PKA, cAMP-dependent protein kinase; Rp-cAMPS, adenosine 3',5'-cyclic monophosphorothioate, Rp-isomer, triethylammonium salt; SDS, sodium dodecyl sulfate; SUb proteins, detergent (NP40), soluble ubiquitinated proteins; Suc-LLVY-AMC, succinyl-Leu-Leu-Val-Tyr-7-amino-4-methylcoumarin; Ub proteins, ubiquitinated proteins

Received 13.12.11; revised 10.5.12; accepted 10.5.12; Edited by D Bano
} 
a

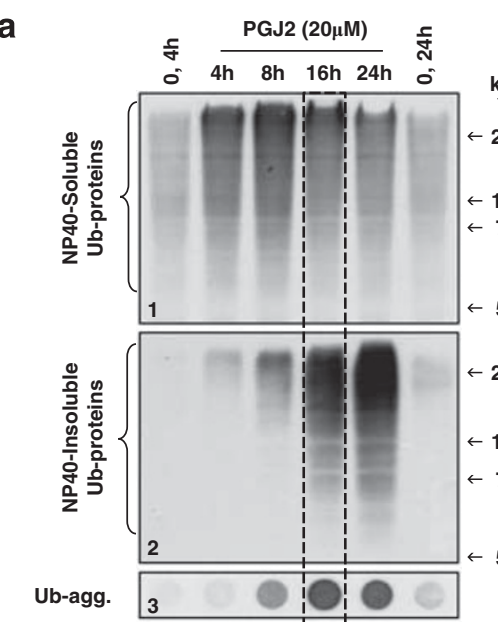

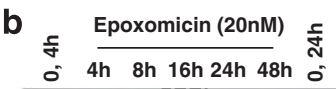
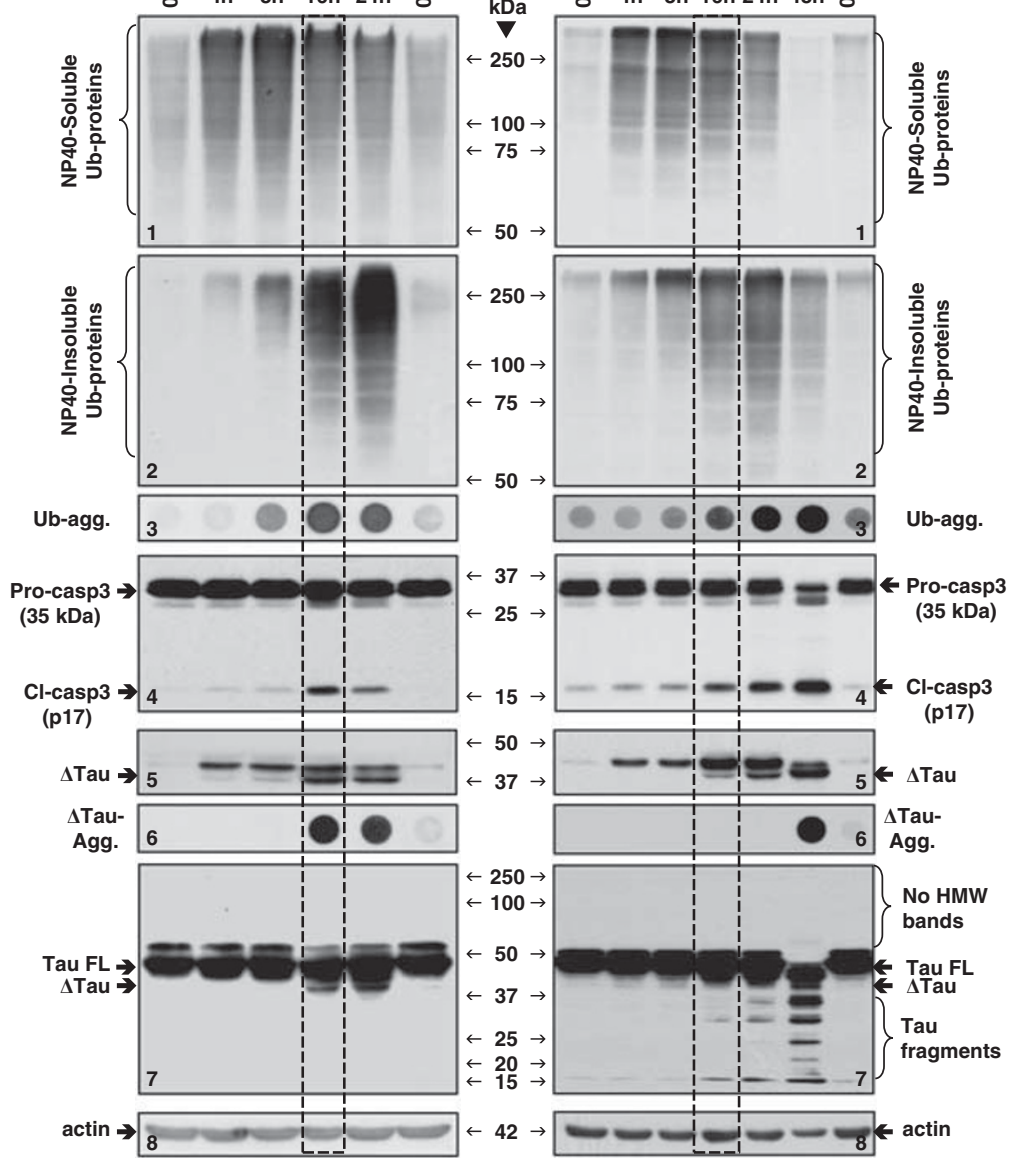

$\leftarrow 42 \rightarrow-\infty-1-\frac{1}{8} *$ actin
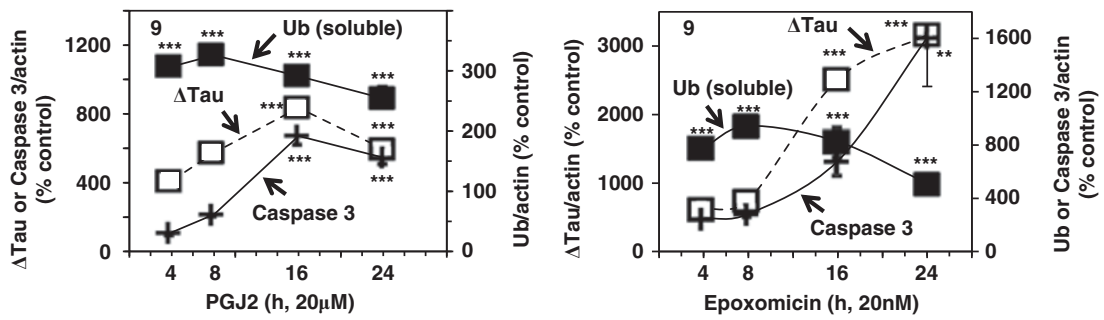

NATIVE PAGE
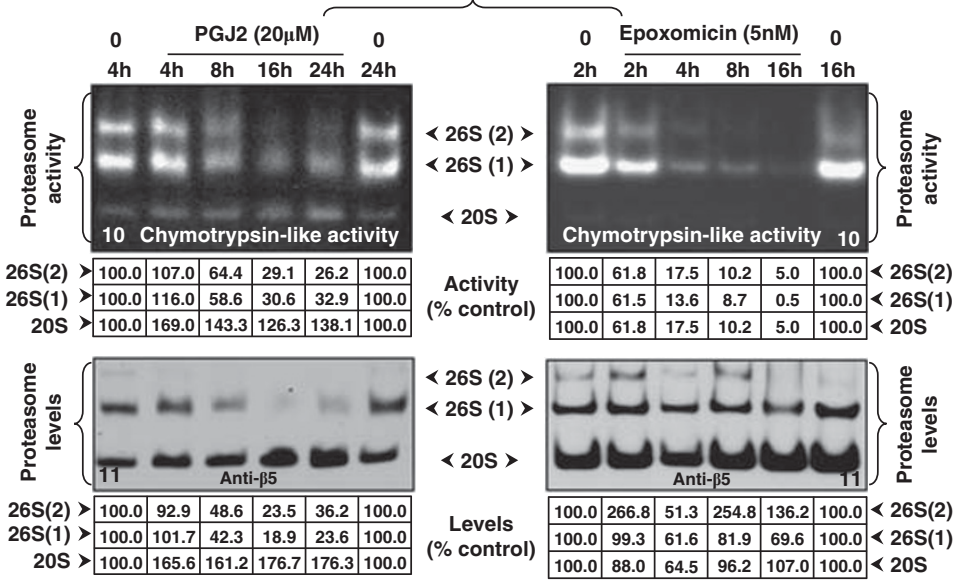

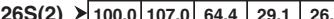

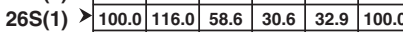
\begin{tabular}{|l|l|l|l|l|l|l|}
\hline $20 S$ & 100.0 & 169.0 & 143.3 & 126.3 & 138.1 & 100.0 \\
\hline
\end{tabular}

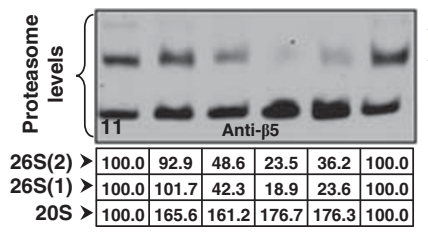

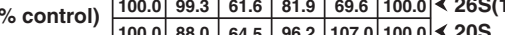


to induce apoptosis via caspase activation in rat cortical neurons, but Ub protein accumulation/aggregation and TAU pathology were not addressed. ${ }^{13}$

We report now that in rat cortical neurons, the buildup of detergent (NP40) -soluble Ub (SUb) proteins induced by PGJ2 or epoxomicin was detected significantly earlier than caspase activation, $\triangle T A U$ and TAU/Ub-protein aggregation. In addition, to our knowledge, we are the first to report that elevating CAMP via treatment with a single dose of dibutyrylcAMP (db-cAMP) or the lipophilic peptide PACAP27 prevents caspase activation, $\triangle T A U$ and protein aggregation induced by short-term incubations (up to $8 \mathrm{~h}$ ) with PGJ2. In the cortical neurons, db-cAMP alone also increased 26S proteasome activity significantly, and reduced 265 proteasome inhibition by PGJ2. Furthermore, db-cAMP and PACAP27 offered neuroprotection against short-term incubations with PGJ2. In long-term studies $(24 \mathrm{~h})$, three consecutive doses of the cAMP-elevating drugs administered $4 \mathrm{~h}$ apart, reduced changes induced by PGJ2. Altogether, these data support the notion that targeting the cAMP/PKA (cAMP-dependent protein kinase) pathway to stimulate $26 \mathrm{~S}$ proteasome activity in a robust and sustainable manner could prevent the early accumulation of SUb proteins, and later avoid caspase activation leading to TAU cleavage and TAU pathology. If applied early before neurons reach a point of no return, elevating cAMP could be an effective therapeutic strategy to prevent/delay neurodegeneration associated with protein aggregation in $A D$.

\section{Results}

Detergent (NP40) -SUb proteins accumulate early upon proteasome inhibition, and before caspase activation, as well as $\triangle$ TAU formation. We investigated a temporal correlation between proteasome inhibition and caspase activation by treating rat cortical neurons with PGJ2 (Figure 1a) or epoxomicin (Figure 1b). The time-course studies clearly demonstrate that detergent (NP40) -SUb proteins are detected upon a $4 \mathrm{~h}$ treatment with $20 \mu \mathrm{M}$ PGJ2 or $20 \mathrm{nM}$ epoxomicin (Figures $1 \mathrm{a}$ and b, panel 1), the earliest time point analyzed. Robust aggregates of Ub proteins, as well as caspase 3 activation, $\triangle T A U$ formation and TAU aggregates (Figures $1 \mathrm{a}$ and $\mathrm{b}$, panels 2 to 6, respectively) were detected much later, that is, after at least $16 \mathrm{~h}$ of treatment. Large (>0.2 $\mu \mathrm{m})$, sodium dodecyl sulfate (SDS)insoluble Ub- and TAU aggregates were assessed with the filter trap assay. Remarkably, the decline in SUb proteins observed at 16 and $24 \mathrm{~h}$ corresponds to a robust increase in Ub aggregates. SUb proteins are considered here to be those that are NP40-soluble, and Ub aggregates those that are NP40-insoluble as well as those that are retained with the filter trap assay.

It is important to clarify that the TAU C3 antibody, which specifically detects TAU cleaved at Asp421 ( $\triangle T A U$, epitope (Ep) a.a. 412-421), reacts with two bands. The upper band is often detected under control conditions, that is, in cells treated with dimethyl sulfoxide (DMSO; vehicle) alone. The lower band concurs with TAU aggregates and appears only under conditions of robust caspase activation (see Figures $1 \mathrm{a}$ and b, panels 4 and 5). We thus consider the lower band to be the major product of caspase cleavage of TAU at Asp421. Probing the western blots with the TAU C5 antibody (Ep a.a. 210-241, Figures $1 \mathrm{a}$ and $\mathrm{b}$, panel 7 ) detected the entire full-length TAU isoforms (Tau FL) as well as $\triangle T A U$, the latter with a pattern similar to the one obtained with the TAU C3 antibody.

Notably, proteasome inhibition for $48 \mathrm{~h}$ with epoxomicin did not increase the level of full-length TAU nor did it generate high-molecular-weight forms of TAU corresponding to UbTAU (Figure 1b, panel 7). Instead, epoxomicin caused an accumulation of various TAU fragments ranging in size between $37 \mathrm{kDa}$ and $15 \mathrm{kDa}$, thus smaller than $\triangle T A U$. These data indicate that upon TAU cleavage at Asp421 by caspases, TAU is further cleaved by unidentified proteases that generate smaller fragments detected upon proteasome inhibition. Actin levels (Figures 1a and b, panel 8) were not altered by the treatments.

We assessed with the native in gel assay, the effects of PGJ2 and epoxomicin on proteasome activity and levels in the cortical neurons. This assay detects the three native proteasome forms: $26 S$ with two regulatory caps [26S(2)] or one cap [26S(1)], and the $20 S$ core particle alone (20S). Proteasome chymotrypsin-like activity was determined with the substrate succinyl-Leu-Leu-Val-Tyr-7-amino-4-methylcoumarin (SucLLVY-AMC; Figures $1 \mathrm{a}$ and $\mathrm{b}$, panel 10). Under control conditions (first lanes), the activity of the $20 \mathrm{~S}$ proteasome is substantially lower than the 26S, because the $20 \mathrm{~S}$ is a latent form of the proteasome. ${ }^{14}$ Proteasome levels were

\footnotetext{
Figure 1 Accumulation of NP40-SUb proteins paves the way for caspase 3 activation, caspase-mediated TAU cleavage $(\triangle T A U)$ and aggregation of Ub proteins as well as TAU, induced by PGJ2 (a) or epoxomicin (b). Western blot analyses to detect Ub proteins (NP40-soluble and NP40-insoluble), caspase 3, TAU cleaved at Asp421 ( $\triangle$ Tau), full-length TAU (Tau FL) and actin (loading control) in cell extracts of rat E18 cerebral cortical neurons ( $40 \mu \mathrm{g}$ of protein/lane). The cortical neurons were treated with $20 \mu \mathrm{M}$ PGJ2 (a) or $20 \mathrm{nM}$ epoxomicin (b) for different time points. Cell extracts were subjected to centrifugation to separate the NP40-soluble and NP40-insoluble fractions as described under 'Materials and Methods'. The blots were probed with anti-Ub proteins antibody (panels 1, 2 and 3), caspase 3 (panel 4), TAU C3 antibody (TAU cleaved at Asp421, epitope a.a. 412-421, panels 5 and 6), TAU C5 antibody (detects all TAU isoforms and $\triangle$ TAU; ep: a.a. 210-241, panel 7) and anti-actin antibody (panel 8). Molecular mass markers in $\mathrm{kDa}$ are shown in the middle. Ub aggregates (Ub-agg.) and $\Delta \mathrm{TAU}$ aggregates ( $\Delta \mathrm{Tau}$-agg.) were analyzed with the filter trap assay ( $50 \mu \mathrm{g}$ of protein/dot, panels 3 and 6). The levels of NP40-soluble Ub proteins (solid squares), cleaved caspase 3 (crosses) and $\triangle$ TAU (open squares) were semi-quantified by densitometry (panel 9). Data represent the percentage of the pixel ratio for soluble Ub proteins, cleaved caspase 3 or $\triangle T A U$, over actin for each condition compared with control (100\%). Values are means \pm S.D. from at least two experiments. Asterisks identify values that are significantly different from control $\left({ }^{* *} P<0.01,{ }^{* \star *} P<0.001\right)$. Ub proteins, Ub proteins; $\triangle \mathrm{Tau}, \mathrm{TAU}$ cleaved at Asp421; Tau FL, full-length TAU. To assess changes in proteasome activity, cell extracts were prepared from rat E18 cerebral cortical neurons treated with $20 \mu \mathrm{M}$ PGJ2 (a) or $5 \mathrm{nM}$ epoxomicin (b) for different time points. Clear lysates ( $30 \mu \mathrm{g} / \mathrm{sample}$ ) were subjected to non-denaturing gel electrophoresis as described under 'Materials and Methods'. 26S and 20S proteasomal (indicated in the middle by arrows) chymotrypsin-like activity was assessed with Suc-LLVY-AMC by the in gel assay (panel 10). Proteasome levels were detected by immunoblotting with the anti- $\beta 5$ antibody (panel 11). The numbers at the bottom of panels 10 and 11 represent $26 \mathrm{~S}$ and $20 \mathrm{~S}$ proteasomal chymotrypsin-like activity and levels, respectively, under each treatment condition. Percentages represent the ratio between data for each condition and control (DMSO) considered to be $100 \%$. Values are means from duplicate experiments
} 
established by immunoblotting with an anti- $\beta 5$ antibody (Figures $1 \mathrm{a}$ and $\mathrm{b}$, panel 11). The $\beta 5$ subunit is a component of the $20 \mathrm{~S}$ core, thus the antibody detects both $26 \mathrm{~S}$ and the $20 S$ proteasomes. PGJ2 and epoxomicin inhibited the $26 \mathrm{~S}$ proteasome in a manner that parallels the accumulation of $\mathrm{Ub}$ proteins induced by both drugs. Furthermore, PGJ2 caused $26 S$ proteasome disassembly, whereas 205 proteasome levels increased (Figure 1a, panel 11). We used lower epoxomicin concentrations in this assay to be able to determine the gradual time-dependent decrease in proteasome activity, which by $16 \mathrm{~h}$ was low (Figure $1 \mathrm{~b}$, panel 10).

$\mathrm{db}-\mathrm{cAMP}$ and PACAP27 prevent the decrease in CAMP induced by PGJ2. PGJ2 is derived from prostaglandin D2 (PGD2), the major product of cyclooxygenases in the mammalian central nervous system. ${ }^{15}$ PGJ2 signals via one of the PGD2 receptors, that is, the DP2 receptor, which is coupled to inhibitory G proteins thus lowering CAMP. ${ }^{16,17}$ As cAMP has neuroprotective effects, ${ }^{18}$ to overcome the decline in CAMP induced by PGJ2, we tested two drugs: (1) $\mathrm{db}-\mathrm{cAMP}$, which is more cell permeable and resistant to cyclic phosphodiesterases than cAMP $^{19}$ and (2) PACAP27 (pituitary adenylate cyclase-activating polypeptide), which is a lipophilic peptide that binds to the seven transmembrane G-coupled receptor PAC1R (pituitary adenylate cyclase 1 receptor) at nanomolar levels, activating adenylate cyclase and elevating $C A M P .{ }^{20}$ PAC1R is expressed in the cerebral cortex, hippocampus and other brain areas. ${ }^{21}$ In our studies, $\mathrm{db}$-cAMP was added to the cultures $30 \mathrm{~min}$ before PGJ2, whereas PACAP27 was added in conjunction with PGJ2.

Compared with control conditions, PGJ2 (10 $\mu \mathrm{M}, 4 \mathrm{~h})$ decreased cAMP levels by almost 3-fold, whereas db-cAMP $(1 \mathrm{mM})$ and PACAP27 (100 nM) increased cAMP by 4-fold and 2.5-fold, respectively (Figure 2). In the presence of PGJ2, dbcAMP and PACAP27 still raised cAMP levels, by 8.4-fold and 4.8fold, respectively, when compared with PGJ2 alone. Remarkably,

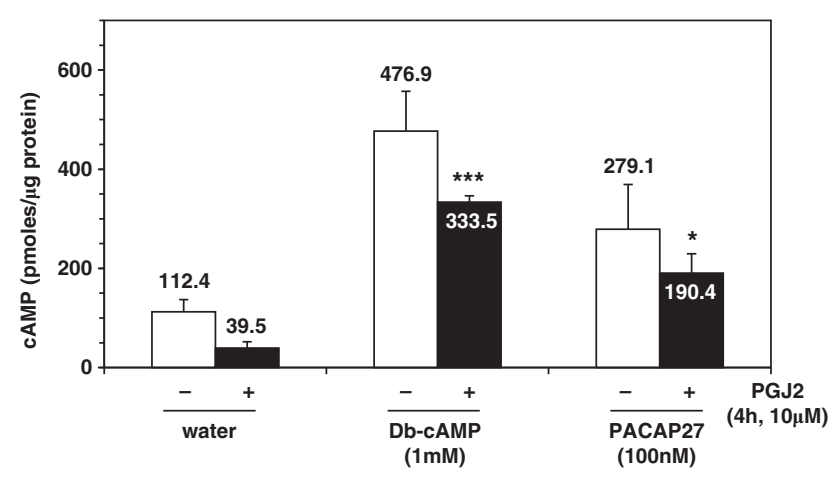

Figure 2 Dibutyryl-cAMP (db-cAMP) and PACAP27 prevent the decrease in cAMP induced by PGJ2. Rat E18 cerebral cortical neurons were treated with water (vehicle, control), db-cAMP $(1 \mathrm{mM})$ or PACAP27 $(100 \mathrm{nM})$ in conjunction with DMSO (vehicle, control, white bars) or with $10 \mu \mathrm{M}$ PGJ2 (black bars) for $4 \mathrm{~h}$. Intracellular CAMP was measured with an EIA kit as described under 'Materials and Methods'. Levels of intracellular cAMP in the cortical neurons are expressed as pmoles per $\mu \mathrm{g}$ of protein. Values represent means and S.E. from three experiments. Asterisks identify values that are significantly different in a comparison between PGJ2 alone and PGJ2 with db-cAMP $\left({ }^{* * *} P<0.001\right)$ or between PGJ2 alone and PGJ2 with PACAP27 $\left({ }^{*} P<0.05\right)$
PACAP27 elevated intracellular cAMP at drastically lower (nanomolar) concentrations than db-cAMP (millimolar).

Db-cAMP and PACAP27 prevent activation of caspases 8 and 3 induced by PGJ2. PGJ2 treatment promotes activation of the initiator caspase 8 (extrinsic pathway) in a time-dependent manner (Figure 3a) similar to activation of the effector caspase 3 (Figure 1a, panel 4). Caspase activation was assessed by western blotting that detects conversion of pro-caspase 8 and 3 into their cleaved active forms, and with a colorimetric assay (Figure 3). Caspases 3 (Figure $3 \mathrm{c}$ ) and 8 (Figure $3 \mathrm{~d}$ ) were significantly ( twofold, $P<0.001)$ activated by $\mathrm{PGJ} 2$ treatment $(8 \mathrm{~h}, 10 \mu \mathrm{M})$. Db-cAMP and PACAP27 stopped/reduced caspase activation triggered by PGJ2 (Figures $3 c$ and d). Caspase 9 was not affected by PGJ2 (Figures $3 b$ and e).

Db-cAMP and PACAP27 prevent $\triangle T A U$ formation induced by PGJ2. The formation of $\triangle T A U$ triggered by short-term (up to $8 \mathrm{~h}$ ) incubations with PGJ2 was blocked/ reduced by db-cAMP (1 mM) and PACAP27 (100 nM; rows 1, Figures $4 a$ and $b)$, respectively. A similar trend was observed for activation of caspase 8 and 3 . Both cAMP-elevating drugs prevented/diminished the conversion of procaspase 8 and 3 to the respective cleaved forms upon short-term (up to $8 \mathrm{~h}$ ) treatment with PGJ2 $(10 \mu \mathrm{M}$, rows 2 and 3, Figures $4 \mathrm{a}$ and b).

Upon long-term (16 and $24 \mathrm{~h}$ ) incubations with PGJ2, the protective effect of a single dose of db-cAMP or PACAP27 related to $\triangle T A U$ and caspase activation was dissipated. PACAP27 was less efficient than db-cAMP at all times. The lanes from each gel were separated into consecutive pairs to facilitate comparing the effect of PGJ2 alone $(-)$ with the combination of PGJ2 plus db-cAMP or PACAP27 $(+)$.

These data demonstrate that elevating intracellular CAMP prevents caspase-dependent $\triangle T A U$ formation triggered by short-term incubations (up to $8 \mathrm{~h}$ ) with PGJ2. The protective effect of one single dose of db-cAMP or PACAP27 against longer PGJ2 treatments (16 and $24 \mathrm{~h}$ ) faded away.

Db-cAMP stimulates proteasomal activity in a PKAdependent manner and reduces $26 \mathrm{~S}$ proteasome inhibition by PGJ2. One single dose of db-cAMP (1 mM) increased the activity and levels of both forms of the $26 \mathrm{~S}$ proteasome in the cortical neurons (Figures $5 a$ and b, panel 1, lane d). The activity of the $20 \mathrm{~S}$ particle was also elevated without major changes in its levels. cAMP is known to exert its action by targeting PKA and/or Epac (exchange protein directly activated by cAMP) (reviewed in Cheng et $a l^{22}$ ). We show that stimulation of the proteasome by $\mathrm{db}$ cAMP was PKA dependent, as it was abolished by pretreatment with adenosine 3',5'-cyclic monophosphorothioate (RpcAMPS; Figures $5 \mathrm{a}$ and $\mathrm{b}$, panel 1, lanes $d$ and e). Rp-cAMPS is a PKA inhibitor that acts as a competitive antagonist of the cyclic-nucleotide-binding domains on PKA. ${ }^{23}$

Db-cAMP reduced the inhibitory effect of PGJ2 on the $26 S$ proteasome, albeit proteasome activity and levels were not completely preserved (Figures $5 \mathrm{a}$ and b, panel 2, compare lanes $b$ and $d$ ). In addition, db-cAMP alone increases proteasome activity via PKA. 


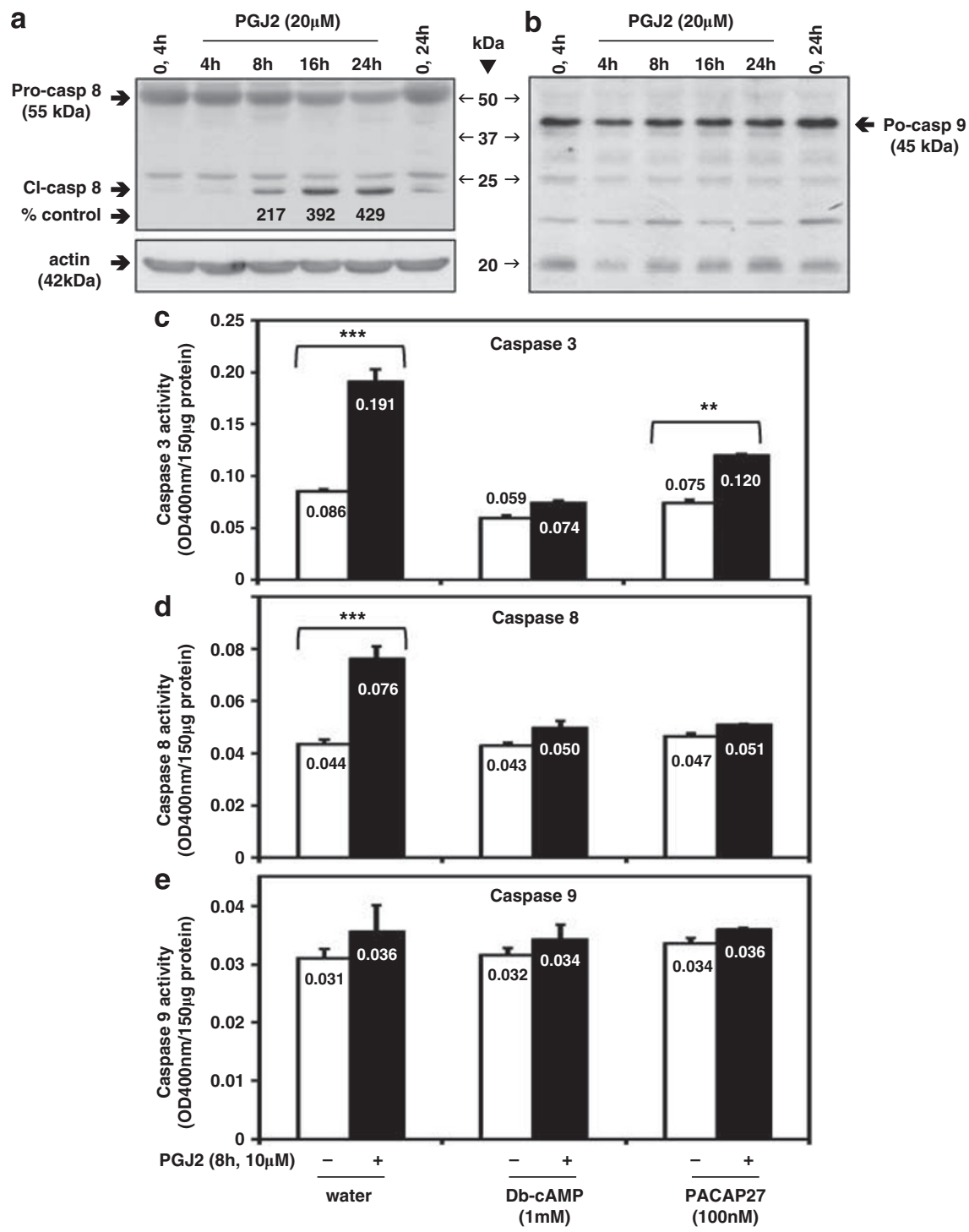

Figure 3 PGJ2-treatment activates caspase 8 (a) in a time-dependent manner, but not caspase 9 (b). Db-cAMP $(1 \mathrm{mM})$ and PACAP27 (100 nM) prevent/reduce caspase 3 and caspase 8 activation induced by PGJ2. Western blot analyses to detect caspases 8 (a) and caspase 9 (b) in their zymogenic (Pro) and cleaved (Cl) forms, and actin (loading control), in extracts ( $40 \mu \mathrm{g}$ of protein/lane) of rat E18 cerebral cortical neurons treated with $20 \mu \mathrm{M}$ PGJ2 for different time points. The blots were probed with the respective antibodies. The numbers in (a) represent the \% increase in cleaved caspase 8 compared with control (100\%). Values are from triplicate experiments. The control value was calculated as the average between controls for 4 and $24 \mathrm{~h}$, reflecting the average of six values. Activities of caspases 3,8 and 9 (c, $\mathbf{d}$ and $\mathbf{e}$, respectively) were also determined in extracts of rat E18 cerebral cortical neurons ( $150 \mu \mathrm{g}$ of protein/assay) as described under 'Materials and Methods'. The cortical neurons were treated with water (vehicle, control), db-cAMP $(1 \mathrm{mM})$ or PACAP27 $(100 \mathrm{nM})$ in conjunction with DMSO (vehicle, control, white bars) or with $10 \mu \mathrm{M}$ PGJ2 (black bars) for $8 \mathrm{~h}$. Caspase activities expressed as OD at $400 \mathrm{~nm}$ and normalized for protein (150 $\mu \mathrm{g} /$ assay) represent means and S.E. from four determinations. Asterisks identify values that are significantly different in a comparison between water, db-cAMP or PACAP27 alone (white bars) and water, db-cAMP or PACAP27 with PGJ2 (black bars), ${ }^{\star \star} P<0.01$ and ${ }^{\star \star \star} P<0.001$

Although PACAP27 elevates cAMP, we did not observe any effect of the peptide on $26 \mathrm{~S}$ proteasomes upon $24 \mathrm{~h}$ treatment (Figures $5 \mathrm{a}$ and $\mathrm{b}$, all panels, lanes $f$ and $g$ ). This is most likely due to rapid hydrolysis of cAMP generated by treatment with the peptide (see Discussion).

Db-cAMP and PACAP27 prevent the formation of Ub protein aggregates induced by PGJ2. Both CAMP-elevating drugs prevented $\mathrm{Ub}$-protein aggregation induced by $8 \mathrm{~h}$ treatment with PGJ2 (Figure 6a, upper pane). However, this effect was dissipated upon longer (24h) PGJ2 incubations
(Figure 6a, lower panel). Db-cAMP reduced $26 \mathrm{~S}$ proteasome inhibition induced by $8 \mathrm{~h}$ as well as $24 \mathrm{~h}$ treatments with PGJ2, but proteasome activity was never recovered to $100 \%$ (Figure 6b). Thus, the beneficial effect of one single dose of $\mathrm{db}$-cAMP on the proteasome effectively prevented protein aggregation upon short-term but not long-term treatment with PGJ2. For simplicity, only the activity of the $26 \mathrm{~S}$ proteasome with one cap [26S(1)] was quantified, as it is the strongest of the three proteasome forms detected.

The levels of NP40-SUb proteins induced by PGJ2 were not altered by db-cAMP (Figures $6 c$ and d) or PACAP27 (not shown). 

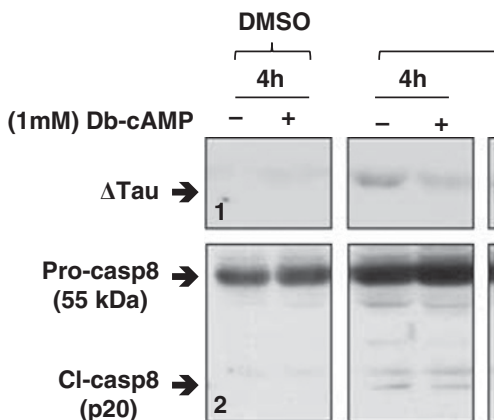

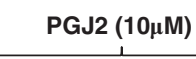

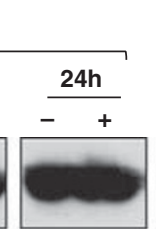

DMSO
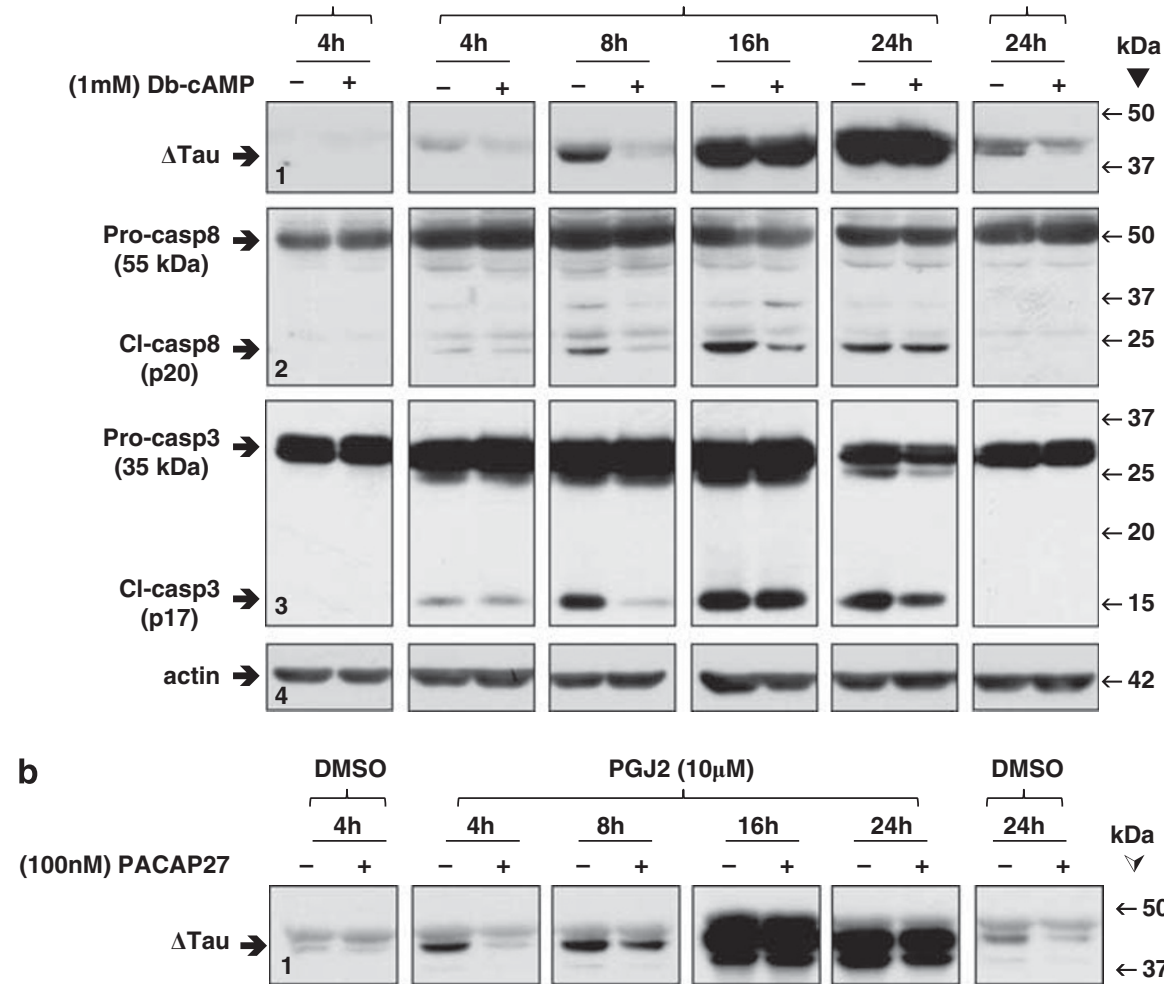

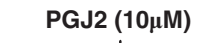
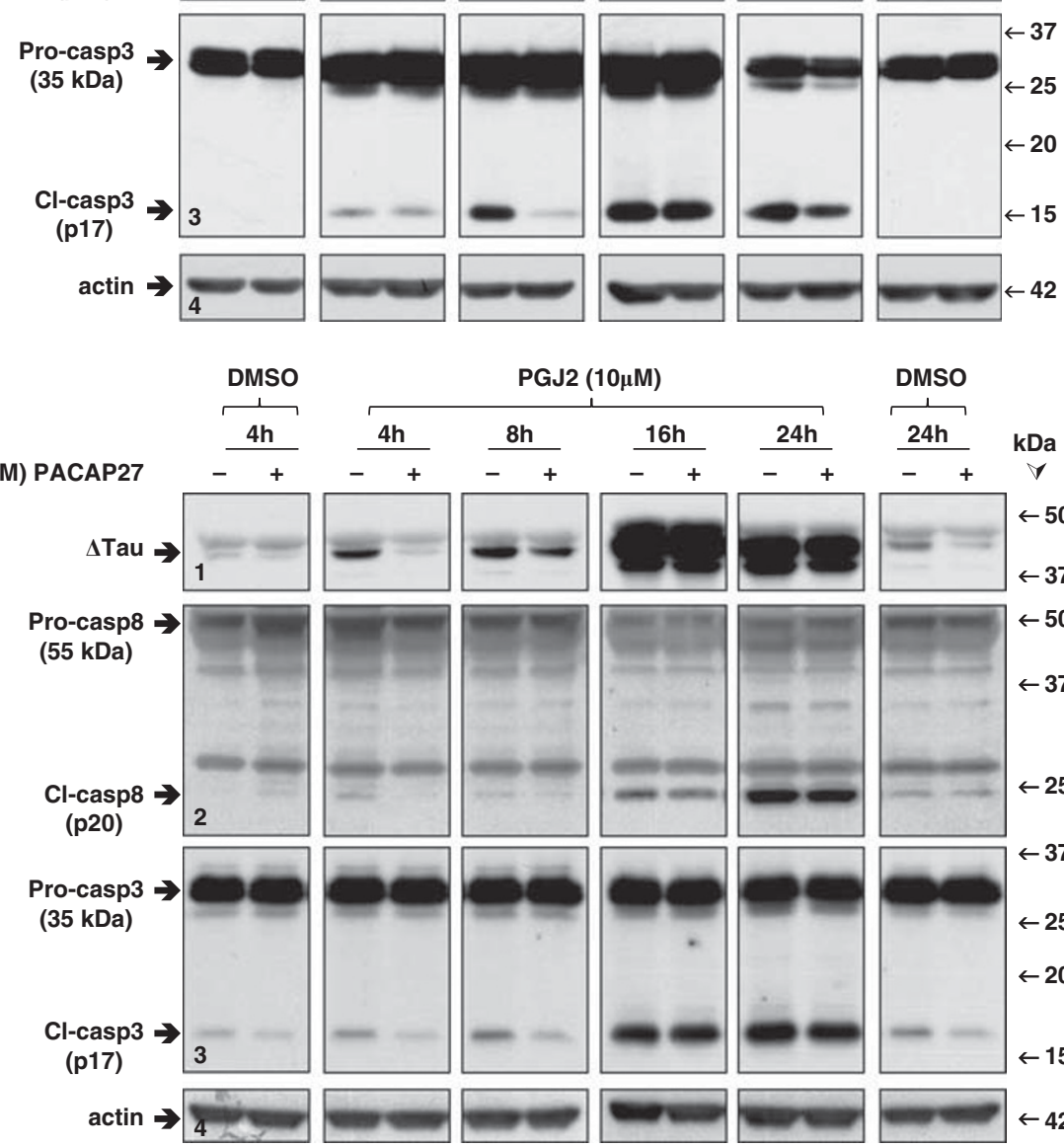

DMSO

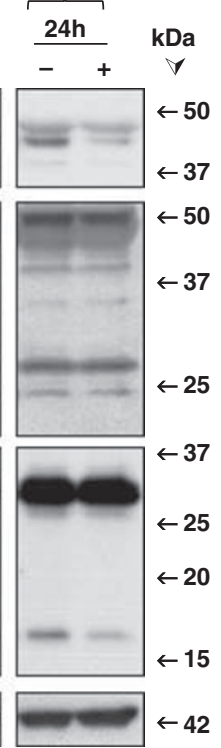

Figure 4 Db-cAMP $(1 \mathrm{mM}, \mathbf{a})$ and PACAP27 $(100 \mathrm{nM}, \mathbf{b})$ prevent/reduce caspase-mediated cleavage of TAU at Asp421 ( $\triangle T A U)$ induced by short-term (up to $8 \mathrm{~h})$ but not long-term (at least $16 \mathrm{~h}$ ) incubations with PGJ2. Western blot analyses to detect TAU cleaved at Asp421 ( $\triangle T A U$, rows 1), caspase 8 (rows 2), caspase 3 (rows 3) and actin (rows 4, loading control) in extracts of rat E18 cerebral cortical neurons ( $40 \mu \mathrm{g}$ of protein/lane). The cortical neurons were treated with water (minus sign, vehicle, control), db-cAMP ((a) plus sign, $1 \mathrm{mM}$ ) or PACAP27 ((b) plus sign, $100 \mathrm{nM}$ ) in conjunction with DMSO (vehicle, control) or $10 \mu \mathrm{M}$ PGJ2 for different time points (4, 8, 16 and $24 \mathrm{~h})$. The blots were probed with the respective antibodies. Molecular mass markers in $\mathrm{kDa}$ are shown on the right. Similar results were obtained in duplicate experiments. $\Delta$ Tau, TAU cleaved at Asp421; Pro, zymogenic; and $\mathrm{Cl}$, cleaved forms of the caspases

We conclude that improvement of proteasome activity by one single dose of db-cAMP was not enough to completely overcome accumulation/aggregation of $\mathrm{Ub}$ proteins. Although $\mathrm{db}$-cAMP reduced $\mathrm{Ub}$ aggregates formed upon $8 \mathrm{~h}$ treatment with PGJ2, in longer treatments the effect of PGJ2 prevailed over the CAMP analog.

Db-cAMP and PACAP27 prevent the loss of cell viability induced by PGJ2. PGJ2 treatment is neurotoxic in a timeand concentration-dependent manner (Figure 7a). Db-cAMP $(1 \mathrm{mM}$, Figures $7 \mathrm{~b}$ and $\mathrm{c}$ ) and PACAP27 $(25-100 \mathrm{nM}$,
Figure $7 d)$ significantly $(P<0.001)$ reduced the loss of viability induced by short-term $(8 \mathrm{~h})$ treatment with PGJ2. However, neuroprotection by a single dose of db-cAMP, the more effective of the two cAMP-elevating drugs, was lost against longer $(24 \mathrm{~h})$ incubations with PGJ2.

Three doses of db-cAMP or PACAP27 reduce the changes induced by long-term $(24 \mathrm{~h})$ incubations with PGJ2. As shown in Figure 7, the viability of the cells upon long-term $(24 \mathrm{~h})$ incubations with PGJ2 decreases to about $50 \%$. To overcome the long-term effects of PGJ2, we 

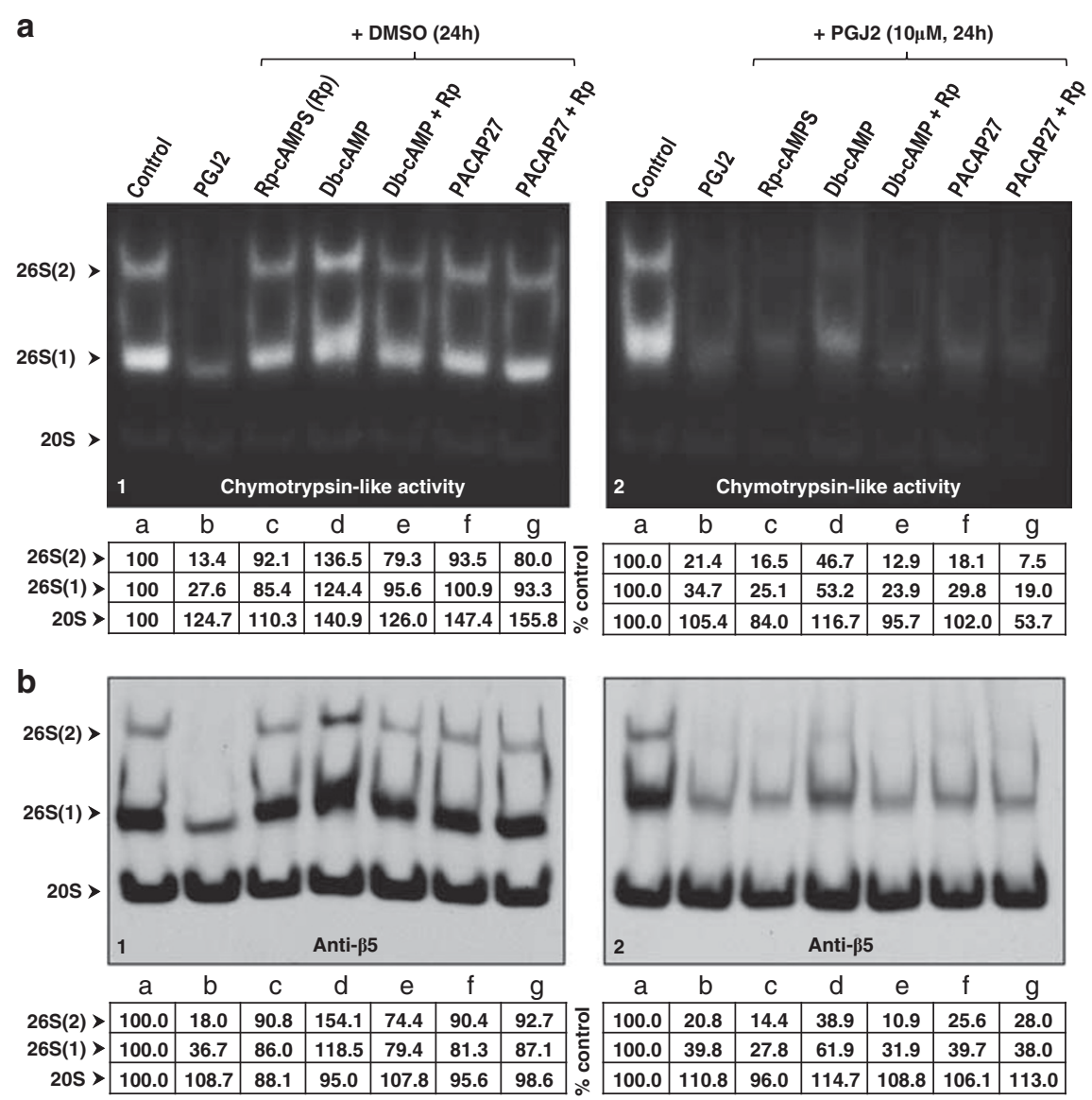

Figure 5 Db-cAMP stimulates 26S proteasomes via PKA, and reduces 26S proteasome inhibition by PGJ2; no changes in 26S proteasome activity were detected with PACAP27. Extracts were prepared from rat E18 cerebral cortical neurons treated with water (control, vehicle), db-cAMP ( $1 \mathrm{mM}$, db-cAMP) without or with Rp-cAMPS (100 $\mu$ M, $1 \mathrm{~h}$ pretreatment, Rp), PACAP27 (100 nM) without or with Rp-cAMPS, in conjunction with DMSO (24 h, control, vehicle, panel 1$)$ or with PGJ2 (24h, $10 \mu \mathrm{M}$, panel 2). Rp-cAMPS is a PKA inhibitor. Cleared cell lysates ( $30 \mu \mathrm{g} / \mathrm{sample}$ ) were subjected to non-denaturing gel electrophoresis as described under 'Materials and Methods'. $26 \mathrm{~S}$ and $20 \mathrm{~S}$ proteasomal chymotrypsin-like activities (indicated on the left by arrows) were assessed with Suc-LLVY-AMC by the in-gel assay (a panels 1 and 2). Proteasome levels were detected by immunoblotting with anti- $\beta 5$ (b panels 1 and 2). The numbers at the bottom of each panel represent $26 \mathrm{~S}$ and $20 \mathrm{~S}$ proteasomal chymotrypsin-like activity and proteasome levels under each treatment condition. Percentages represent the ratio between data for each condition and control (DMSO, 100\%). Values are from a representative experiment. Similar results were obtained in duplicate experiments

increased the number of treatments with the cAMP-elevating drugs as described under 'Materials and Methods'. As shown in Figure 8 , three doses of db-cAMP $(1 \mathrm{mM})$ or PACAP27 $(100 \mathrm{nM})$ clearly diminished the levels of $\triangle \mathrm{TAU}$ (panel 1), $\triangle T A U$ aggregates (panel 2), caspase 3 cleavage (panel 3), soluble Ub proteins (panel 4), Ub-protein aggregates (panel 5 ) and loss of cell viability (panel 7 ) induced by $24 \mathrm{~h}$ treatment with $5 \mu \mathrm{M}$ PGJ2. Incubations with $10 \mu \mathrm{M}$ PGJ2 caused more severe changes than $5 \mu \mathrm{M} P \mathrm{PGJ} 2$, and thus were harder to overcome. In the absence of PGJ2, three doses of the cAMP-elevating drugs did not alter the levels of the proteins tested (not shown). In addition, treatment with just two doses of the CAMP-elevating drugs was ineffective against PGJ2 (not shown).

\section{Discussion}

Our current data with rat cerebral cortical neurons demonstrate a temporal correlation between proteasome inhibition and caspase activation that leads to TAU cleavage at Asp421 associated with TAU pathology and cell death. The temporal correlation depicts the accumulation of detergent (NP40)SUb proteins occurring early upon proteasome impairment. Caspase activation, TAU cleavage at Asp421 and the aggregation of TAU and Ub proteins occur significantly later. Large aggregates (detected with the filter trap assay) also appear late in this toxic cascade. The filter trap assay captures large $(>0.2 \mu \mathrm{m})$ and SDS-insoluble aggregates. ${ }^{24}$ The sequence of proteolysis-related events was triggered by the product of inflammation PGJ2 and the specific proteasome inhibitor epoxomicin. Although PGJ2 mimics the effect of some oxidative stressors by causing dissociation of $26 \mathrm{~S}$ proteasomes, ${ }^{9,10}$ epoxomicin forms covalent adducts with the $20 \mathrm{~S}$ proteasome active sites. ${ }^{12}$ The finding that both drugs induce a similar temporal response to proteasome impairment suggests that these proteolysis-related events could be shared by various proteotoxic conditions that induce a decline in proteasome activity in neurons. This temporal response to proteasome inhibition strongly supports the notion that the accumulation of SUb proteins, if not resolved, could be one of 
a

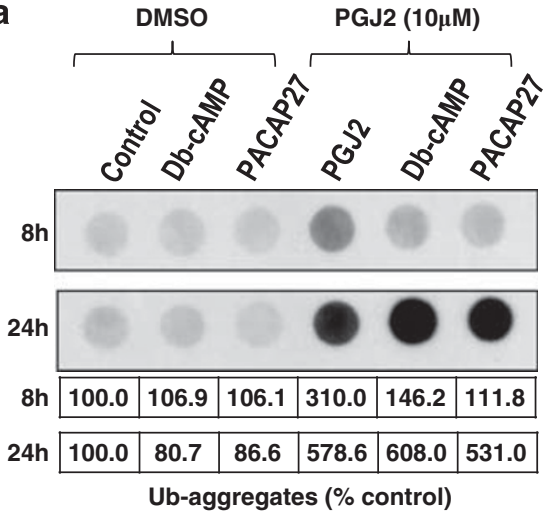

b

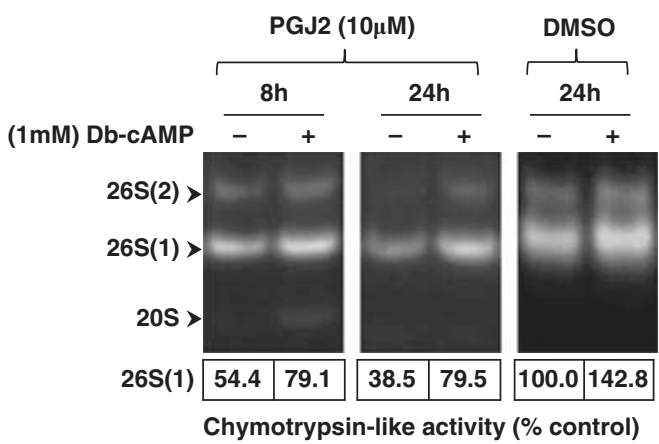

c

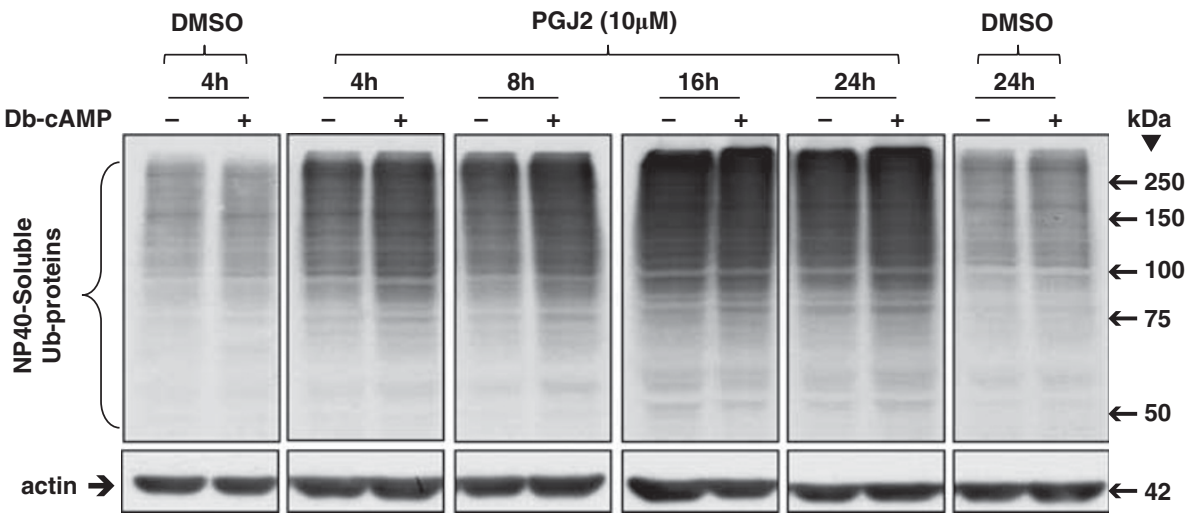

d

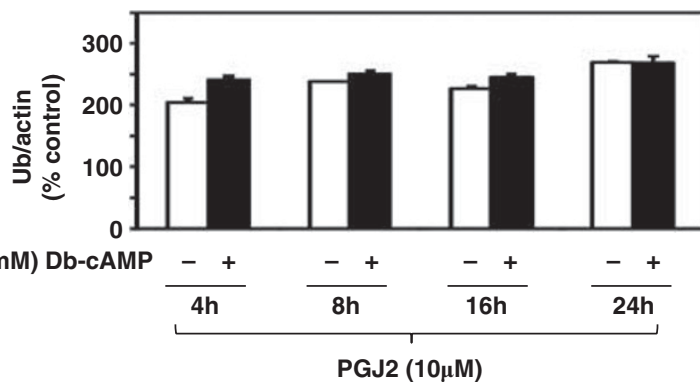

Figure 6 Db-cAMP (1 mM) reduces Ub aggregates and 26S proteasome inhibition induced by PGJ2; accumulation of NP40-soluble Ub proteins triggered by PGJ2 was not affected by db-cAMP. (a) Ub aggregates (50 $\mu \mathrm{g}$ of protein/dot) were analyzed with the filter trap assay as described under 'Materials and Methods'. (b) $26 \mathrm{~S}$ and $20 \mathrm{~S}$ proteasomal chymotrypsin-like activities were assessed with Suc-LLVY-AMC by the in-gel assay as described under 'Materials and Methods'. The numbers under the panels represent in (a) ubiquitin aggregates, and in (b) 26S and 20S proteasomal chymotrypsin-like activity. Percentages represent the ratio between data for each condition and control (DMSO, 100\%). Values are from a representative experiment. Similar results were obtained in duplicate experiments. (c) Western blot analyses to detect NP40-soluble $\mathrm{Ub}$ proteins and actin (loading control) in extracts of rat $\mathrm{E} 18$ cerebral cortical neurons (40 $\mu \mathrm{g}$ of protein/lane). The cortical neurons were treated with water (minus sign, vehicle, control) or db-cAMP ((c) plus sign, $1 \mathrm{mM}$ ) in conjunction with DMSO (vehicle, control) or $10 \mu \mathrm{M}$ PGJ2 for different time points $(4,8,16$ and $24 \mathrm{~h}$ ). The blots were probed with the respective antibodies. Molecular mass markers in $\mathrm{kDa}$ are shown on the right. The levels of NP40-soluble Ub proteins were semi-quantified by densitometry (d). Data represent the percentage of the pixel ratio for soluble Ub proteins over actin for each condition compared with control (100\%). Values are means and S.E. from three experiments

the critical events triggering caspase activation that mediates TAU cleavage and generates aggregation-prone fragments of TAU. Other studies support this notion. For example, 26S proteasome dysfunction was sufficient to trigger neurodegenerative disease in a transgenic mouse model developed by conditionally depleting a $26 \mathrm{~S}$ proteasome subunit in forebrain neurons. ${ }^{25}$ The mutant mice exhibited diffuse accumulation of Ub proteins in forebrain neurons at 2 weeks of age. Caspase activation and intraneuronal Ub-positive inclusions were observed later, at 4 weeks of age, indicating extensive neurodegeneration in the targeted neurons. ${ }^{25}$ In another study, proteasome impairment was found to occur early in the progression of the pathological events detected in $3 \times \mathrm{Tg}-\mathrm{AD}$ mice, leading to $A \beta$ and TAU accumulation. ${ }^{26}$ Based on these studies, we propose that elevating proteasome activity to prevent the accumulation of SUb proteins early in the neurodegenerative process could be an effective approach to prevent caspase activation and TAU pathology.

Notably, we found that a single dose of db-cAMP increases 26 s proteasome activity via PKA activation in the cortical 
neurons. Others established a similar phenomenon in 293 cells ${ }^{27}$ and in myocardium. ${ }^{28}$ The latter studies demonstrated that PKA stimulation increased the activity of the $26 \mathrm{~S}$ proteasome via subunit phosphorylation and/or transcription. In our experiments with the cortical neurons, proteasome stimulation promoted by a single dose of db-cAMP mitigated proteasome inhibition induced by PGJ2. Under the conditions tested, we did not observe proteasome stimulation by PACAP27, although the peptide elevates intracellular cAMP. This is not surprising, as CAMP is significantly more susceptible to hydrolysis by cyclic phosphodiesterases than its analog db-cAMP. Cyclic phosphodiesterases exhibit very rapid kinetics for cAMP degradation, compared with cAMP synthesis by adenylate cyclases. ${ }^{29}$ It is likely that to maintain proteasome activity via db-CAMP or PACAP27 on a long-term basis under proteotoxic conditions, these drugs have to be delivered more than once, and not as a single dose. PACAP27 may be preferred over db-cAMP, as the latter was shown to have adverse biological effects when administered in vivo. ${ }^{30}$ Once prolonged 26S proteasome stimulation is attained, it could prevent the early accumulation of SUb proteins and avoid later on caspase activation, protein aggregation and neurons from reaching a point of no return.

We also demonstrate, for the first time to our knowledge, that elevating cAMP via db-cAMP or PACAP27 prevents caspase activation and generation of $\triangle T A U$ induced by PGJ2. TAU proteolysis is recognized as having an important role in TAU aggregation and neurodegeneration in AD. ${ }^{2,3}$ Thus, blocking TAU cleavage at Asp421 could be a potential therapeutic approach against TAU pathology. We show that only a single dose of db-cAMP or PACAP27 blocked caspase activation and $\triangle T A U$ upon short-term (up to $8 \mathrm{~h}$ ) treatment with PGJ2. As shown in Figure 7, the viability of the cells upon long-term (24h) incubations with PGJ2 decreases to about $50 \%$. To attempt to overcome the harsh effects of long-term (24h) incubations with PGJ2, we decided to increase the number of treatments with the cAMP-elevating drugs. Administration of three sequential doses of the cAMP-elevating drugs was necessary to diminish $\triangle T A U$, caspase activation and loss of cell viability promoted by long-term (24h) incubations with $5 \mu \mathrm{M}$ PGJ2. It is notable that PACAP27 mimics the protective effects of $\mathrm{db}$-cAMP at considerably lower concentrations (nanomolar for PACAP27 versus millimolar for db-cAMP). The difference in effectiveness could be due to some properties of $\mathrm{db}$-cAMP, such as that it remains inactive until endogenous esterases/amylases remove the butyrate. $^{31}$ Furthermore butyrate, by itself, affects gene transcription and PKC, thus interfering with several cAMPdependent pathways. ${ }^{31}$ As discussed above in relation to PACAP27, treatment with a single dose of the peptide is unlikely to be optimal and/or maximized for long-term neuroprotection, because its action depends on the production of hydrolysable cAMP. This notion is supported by our data showing that three consecutive doses of the cAMPelevating drugs diminish long-term $(24 \mathrm{~h})$ effects of PGJ2. Interestingly, PACAP was shown to enhance $\alpha$-secretase activity $^{32}$ and improve memory in rats. ${ }^{33}$ That PACAP27 shows promise in delaying $A D$ is corroborated by a recent study showing that long-term daily intranasal administration of PACAP slowed down AD-like pathology in APP[V717I]
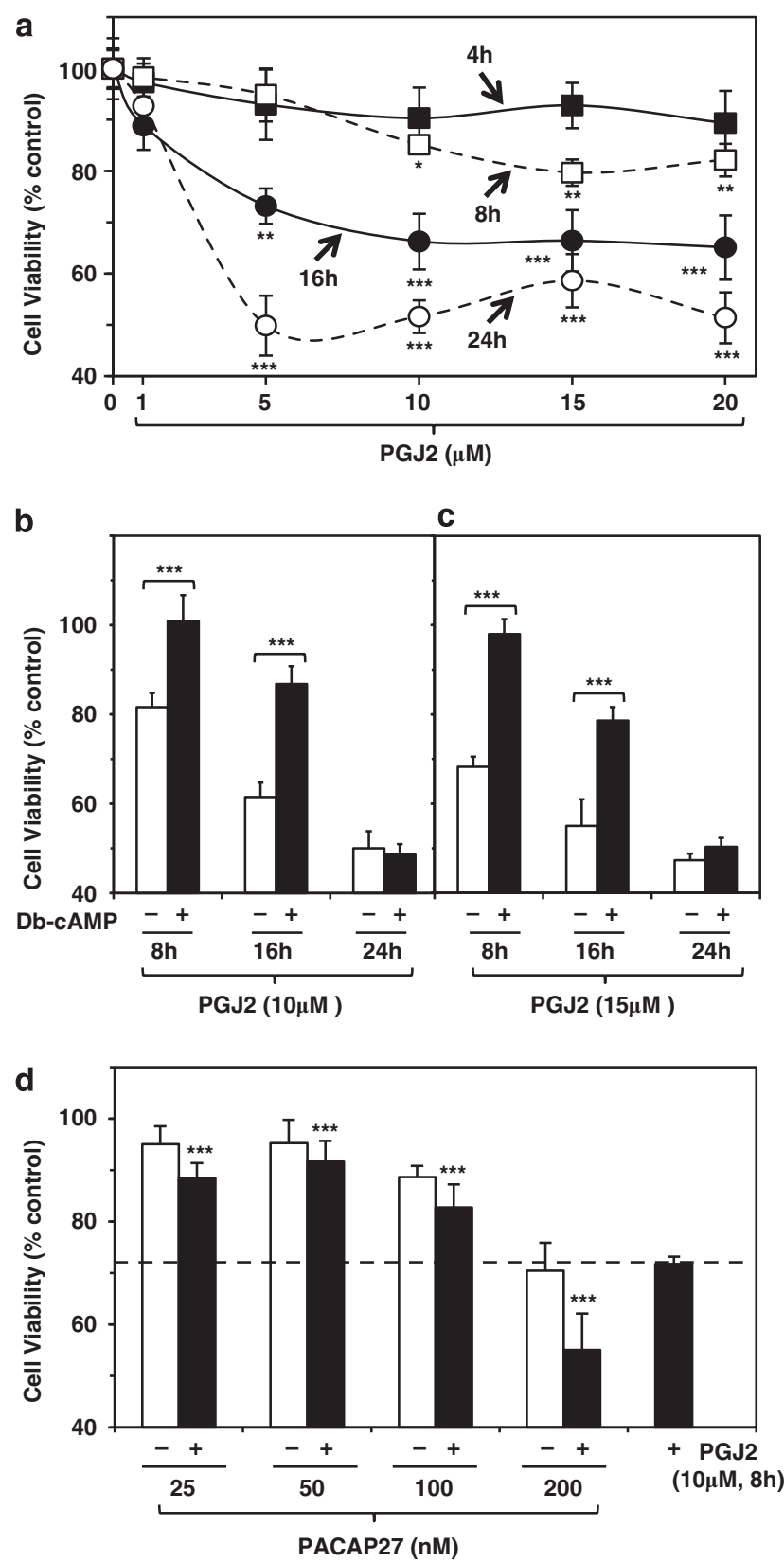

Figure 7 Db-cAMP (1mM) and PACAP (100 nM) prevent/reduce the loss of cell viability induced by short-term ( $8 \mathrm{~h}$ ) incubations with PGJ2. Rat E18 cerebral cortical neurons were treated: in (a) with DMSO $(0$, control), or increasing concentrations of PGJ2 for 4, 8, 16 or $24 \mathrm{~h}$; in (b) and (c) with water (control, vehicle, minus sign) or db-cAMP (1 mM, db-cAMP, plus sign) in conjunction with DMSO (vehicle, not shown) or PGJ2 (b, $10 \mu \mathrm{M}, \mathbf{c}, 15 \mu \mathrm{M}$ ) for 8,16 and $24 \mathrm{~h}$; in (d) with water (control, vehicle, not shown) or with PACAP27 $(25,50,100$ or $200 \mathrm{nM})$ in conjunction with DMSO (vehicle, minus sign) or PGJ2 $(10 \mu \mathrm{M}$, plus sign) for $8 \mathrm{~h}$. Cell viability was assessed with the MTT assay as described under 'Materials and Methods'. Percentages represent the ratio between the data for each condition and control $(100 \%)$. Values indicate means and S.E. from at least three experiments. Asterisks identify values that are significantly different in (a) from control, in (b) and (c) between PGJ2 alone and PGJ2 with db-cAMP, and in (d) between PGJ2 alone and PGJ2 with PACAP27, ${ }^{\star} P<0.05,{ }^{* *} P<0.01,{ }^{* *} P<0.001$

AD transgenic mice. ${ }^{34}$ In the latter studies, TAU pathology was not addressed. Together these results support the view that, due to its beneficial properties, PACAP27 could be a very 

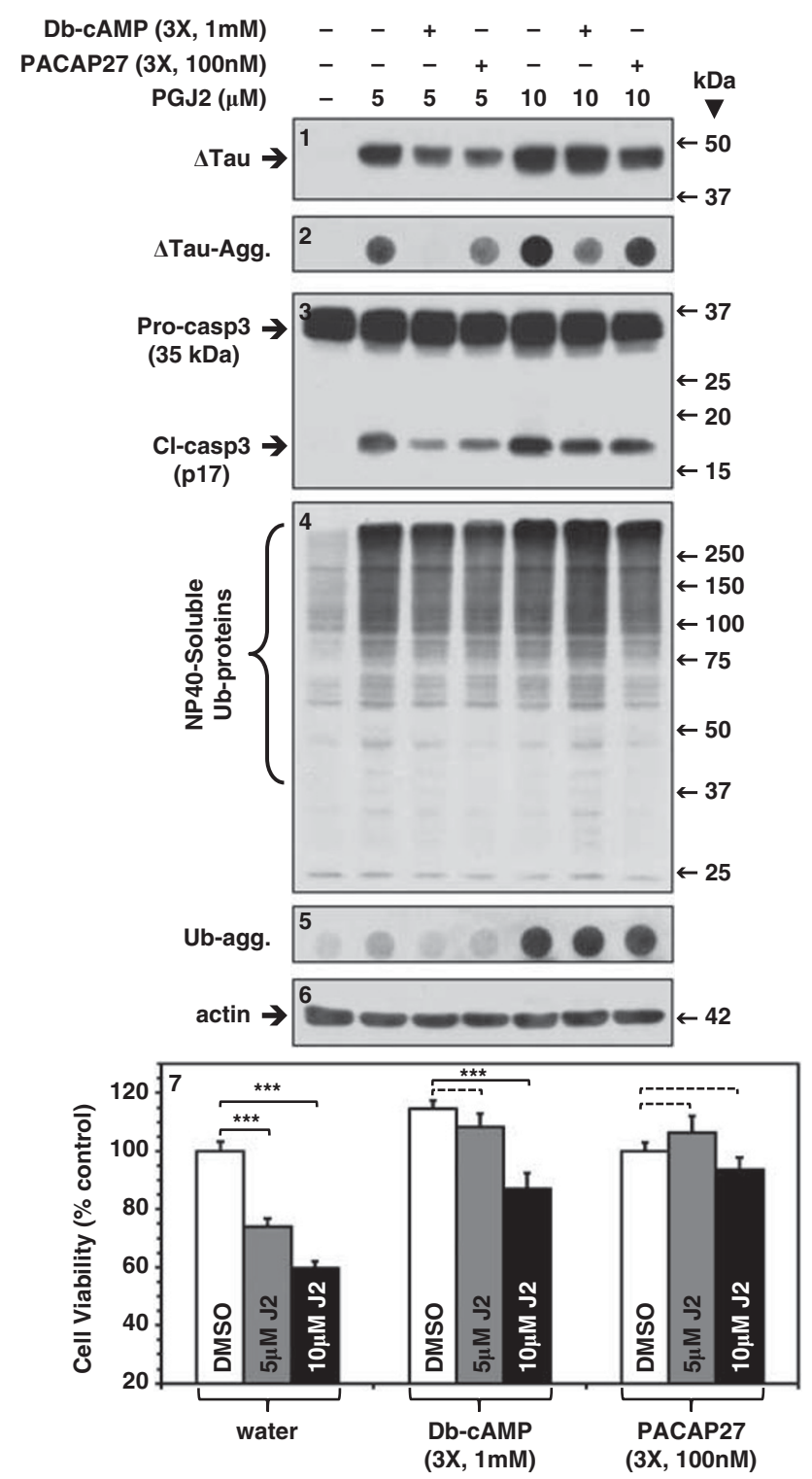

Figure 8 Three doses of db-cAMP $(1 \mathrm{mM})$ or PACAP $(100 \mathrm{nM})$ diminish the effects of long-term (24h) incubations with PGJ2. Rat E18 cerebral cortical neurons were treated with DMSO ( 0 , control, vehicle for PGJ2) or PGJ2 (5 or $10 \mu \mathrm{M})$ in conjunction with three consecutive doses of water (control, vehicle for db-cAMP and PACAP27), db-cAMP (1 mM, db-cAMP) or PACAP27 (100 nM) over a period of $24 \mathrm{~h}$. The cAMP-elevating drugs were added as described under 'Materials and Methods'. Western blots of the NP-40 soluble fractions ( $30 \mu \mathrm{g}$ of protein/lane) were probed for TAU cleaved at Asp421 ( $\triangle \mathrm{TAU}$, panel 1), caspase 3 (panel 3), soluble Ub proteins (panel 4 ) and actin (panel 6, loading control). $\triangle \mathrm{TAU}$ - and Ub aggregates (panels 2 and 5) were assessed with the filter trap assay (30 $\mu \mathrm{g}$ of protein/dot). Molecular mass markers in $\mathrm{kDa}$ are shown on the right. Similar results were obtained in duplicate experiments. $\Delta$ Tau, TAU cleaved at Asp421; Pro, zymogenic; and $\mathrm{Cl}$, cleaved forms of caspase 3. Cell viability (panel 7) was assessed with the MTT assay. Percentages represent the ratio between the data for each condition and control (100\%). Values indicate means and S.E. from six determinations. Asterisks identify values that are significantly different from treatment with water alone or db-cAMP alone (white bars, respectively) within each group, with ${ }^{* \star *} P<0.001$. Dashed lines compare conditions that are not significantly different

interesting agent for long-term treatment of $A D$ (reviewed in Reglodi et $\left.a l .{ }^{35}\right)$. The challenge is to identify which mechanisms PACAP27 is triggering to bring about its protective effects.

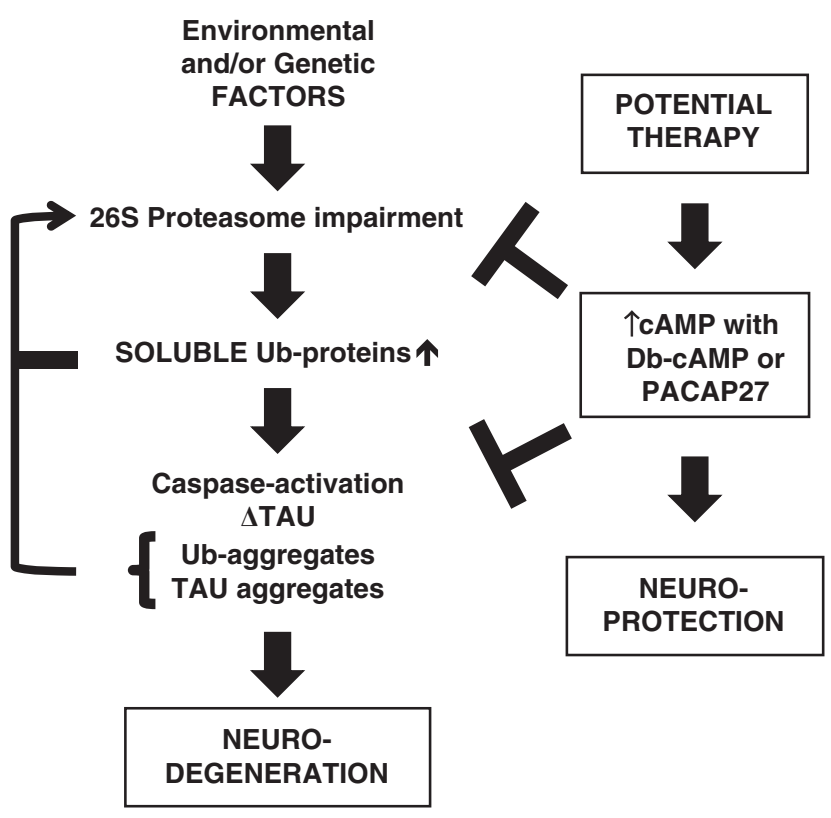

Figure 9 Model for the progression of neurodegeneration and potential therapy. The model is based on proteasome impairment and the early accumulation of detergent soluble Ub proteins. The therapeutic approach focuses on a robust and sustainable stimulation of $26 \mathrm{~S}$ proteasome activity accomplished by targeting cAMP/PKA signaling. Details are provided in the last paragraph of the discussion.

In conclusion, our data clearly demonstrate that the accumulation of SUb proteins is an early event that occurs after treating cortical neurons with two drugs, that is, PGJ2 and epoxomicin, that inhibit the proteasome by different means. As there is compelling evidence for impairment of proteasome activity in $\mathrm{AD}^{36}$ and aging, ${ }^{37}$ it is possible that the sequence of proteolysis-related events that we established here and that are triggered by PGJ2 and epoxomicin is similar in the early stages of neurodegeneration in $A D$ (modeled in Figure 9). Initially, low levels of SUb proteins that escape degradation accumulate in the affected areas of the AD brain. These SUb proteins could further exacerbate proteasome malfunction. Several studies demonstrate that increasing the levels of polyubiquitin chains ${ }^{38}$ and/or aggregation prone proteins, such as PHF-TAU, ${ }^{39}$ decreases proteasome activity. When these proteins accumulate in the cell, they can bind to proteasomes and block access of other substrates to the proteasomal-degradation machinery, thus further aggravating the proteotoxic situation. With time, proteasome activity continues to deteriorate to a point that the neurons can no longer cope with the proteotoxic stress and reach a point of no return. This feed-forward incremental proteasome inhibition could be a major factor in neurodegeneration. We propose (modeled in Figure 9) that targeting the proteasome to enhance its activity in a robust and sustainable manner via cAMP/PKA signaling could avoid the early accumulation of SUb proteins, followed later on, by caspase activation and protein aggregation. An early intervention strategy could prevent neurons from reaching a point of no return, and provide an effective therapy to avoid/delay neurodegeneration in AD. 
Materials and Methods

Materials. PGJ2 was from Cayman Chemical (Ann Arbor, MI, USA) and epoxomicin from Peptides International Inc. (Louisville, KY, USA). Adenosine $3^{\prime}$, $5^{\prime}$-cyclic monophosphate dibutyryl sodium salt (db-cAMP), Rp-cAMPS, triethylammonium salt (Rp-isomer) and the cAMP colorimetric direct immunoassay Kit were from Calbiochem/EMD Bioscience (Gibbstown, NJ, USA). The 3-(4,5dimethylthiazol-2-yl)-2,5-diphenyl-tetrazolium bromide (MTT) was from SigmaAldrich (St. Louis, MO, USA). The substrate Suc-LLVY-AMC and the peptide PACAP27 were from BACHEM Bioscience Inc. (King of Prussia, PA, USA). Antibodies: rabbit polyclonal anti-Ub-proteins (1:1,500, cat\# Z0458, Dako, North America, Carpinteria, CA, USA); rabbit polyclonal anti- $\beta 5$ (1:1,000, cat\# PW8895) from BIOMOL (Plymouth Meeting, PA, USA); mouse monoclonal anti- $\beta$-actin (1:10,000, cat\# A2228, Sigma, St. Louis, MO, USA); rabbit polyclonal anti-caspase 8 (1:500, cat\# 3020) and anti-caspase $9(1: 1,000$, cat\# 3016) from BioVision (Mountain View, CA, USA); mouse monoclonal TAU C3 (1:5,000; detects TAU cleaved at Asp421; Ep: a.a. 412-421) and mouse monoclonal TAU C5 (1:50,000; detects all TAU isoforms and $\triangle \mathrm{TAU}$; Ep: a.a. 210-241) were courtesy of Dr. L Binder (Northwestern University, Chicago, IL, USA); rabbit polyclonal anticaspase 3 (1:1000, cat\# 9662, Cell Signaling Technology, Danvers, MA, USA). The respective secondary antibodies with HRP conjugate $(1: 10,000)$ were from BioRad Laboratories (Hercules, CA, USA).

Cell cultures. Dissociated cultures from Sprague Dawley rat embryonic (E18, both sexes) cerebral cortical neurons were prepared as follows: the isolated cortices free of meninges were digested with papain $(0.5 \mathrm{mg} / \mathrm{ml}$ from Worthington Biochemical Corp., Lakewood, NJ, USA) in Hibernate $E$ without calcium (BrainBits LLC., Springfield, IL, USA) at $37^{\circ} \mathrm{C}$ for $30 \mathrm{~min}$ in a humidified atmosphere containing $5 \% \mathrm{CO}_{2}$. After removal of the enzymatic solution, the tissues were gently dissociated in Neurobasal media (Invitrogen, Carlsbad, CA, USA). Dissociated tissues were centrifuged at $300 \times g$ for $2 \mathrm{~min}$. The pellet was resuspended in Neurobasal media without antibiotics and plated on $10 \mathrm{~cm}$ dishes precoated with $50 \mu \mathrm{g} / \mathrm{ml}$ poly-D-lysine (Sigma). Cells were plated at a density of $6 \times 10^{6}$ cells per $10 \mathrm{~cm}$ dish or $2.5 \times 10^{5}$ cells per well on 24-well plates (cell viability only). Cultures were maintained in Neurobasal media supplemented with $2 \%$ B27 and $0.5 \mathrm{mM}$ glutamine (all from Invitrogen) at $37^{\circ} \mathrm{C}$ in a humidified atmosphere containing $5 \% \mathrm{CO}_{2}$. Half of the medium was changed every 4 days.

Culture treatments. Cortical neurons were treated for $4,8,16$ or $24 \mathrm{~h}$ with DMSO or ultra pure filtered water (controls) or with different drugs: PGJ2 and epoxomicin in DMSO; db-cAMP, Rp-cAMPS and PACAP27 in ultra pure filtered water added directly to DMEM without serum supplemented with $0.5 \mathrm{mM}$ glutamine and $1 \mathrm{mM}$ sodium pyruvate (all from Invitrogen). The final DMSO concentration in the medium was $0.5 \%$. For a single administration, db-cAMP was added to the cultures $30 \mathrm{~min}$ before PGJ2, whereas PACAP27 was added in conjunction with PGJ2. For triple $(3 \times)$ administrations, each of the CAMPelevating drugs was added firstly as for the single administration, and then 4 and $8 \mathrm{~h}$ after that. PGJ2 was added only once at the beginning of the treatment. At the end of the incubations, all cultures were washed twice with phosphate buffered saline (PBS) and processed for the different assays as described below.

Cell viability assay. Cells were treated under various conditions for 4, 8, 16 or $24 \mathrm{~h}$. Cell viability was assessed with the MTT assay as described in Mosmann. ${ }^{40}$

Western blotting. After treatment, cells were rinsed twice with PBS and harvested by gently scraping into ice-cold lysis buffer $(20 \mathrm{mM}$ Tris- $\mathrm{HCl}, \mathrm{pH} 7.5$, $137 \mathrm{mM} \mathrm{NaCl}, 1 \mathrm{mM}$ EGTA, $2.5 \mathrm{mM} \mathrm{Na}_{4} \mathrm{P}_{2} \mathrm{O}_{7}, 1 \mathrm{mM} \beta$-glycerophosphate, $50 \mathrm{mM}$ $\mathrm{NaF}, 1 \mathrm{mM}$ phenylmethylsulfonyl fluoride, $1 \% \mathrm{NP} 40,1 \mathrm{mM} \mathrm{Na}_{3} \mathrm{VO}_{4}, 1 \%$ Glycerol and protease inhibitor cocktail (Sigma-Aldrich)). Following lysis (at least $30 \mathrm{~min}$, $-80^{\circ} \mathrm{C}$ ), cell extracts were centrifuged $(19000 \times g$ for $10 \mathrm{~min})$ at $4^{\circ} \mathrm{C}$ for separation into two fractions: NP40-soluble (supernatant) and NP40-insoluble (pellet). The pellet was resuspended in a buffer containing $1 \%$ SDS and $10 \mathrm{mM}$ Tris-EDTA pH 7.5. Protein concentration of both fractions was determined (BCA kit, Pierce, Rockford, IL, USA). Note that we consider SUb proteins those that are NP40-soluble and Ub aggregates those that are NP40-insoluble as well as detected by the filter trap assay described below. Western blot analysis was carried out following SDS-polyacrylamide gel electrophoresis. Normalized samples were boiled for $5 \mathrm{~min}$ in Laemmli buffer and loaded onto gels ( $40 \mu \mathrm{g}$ of protein/ lane). Following electrophoresis, proteins were transferred onto an Immobilon- $P$ membrane (Millipore, Bedford, MA, USA). The membrane was probed with the respective antibodies, and antigens were visualized by a standard chemiluminescent horseradish peroxidase method with the enhanced chemiluminescence $(E C L)$ reagent. Semi-quantitative analysis of protein detection was done by image analysis with the ImageJ program (Rasband, WS, ImageJ; US NIH, Bethesda, MD, USA; http://rsb.info.nih.gov/ij/).

Filter trap assay. After treatment, media was removed and cells were lysed as for western blotting. Samples were normalized to $0.5 \mu \mathrm{g} / \mu \mathrm{l}$ using a buffer containing $2 \%$ SDS and $10 \mathrm{mM}$ Tris-EDTA pH 7.5. From the different extracts, $50 \mu \mathrm{g}$ of proteins were filtered through a $0.2-\mu \mathrm{m}$ nitrocellulose membrane (BioRad) using a 96-well dot blot apparatus (Schleicher \& Scheull Inc., Keene, NH, USA). Each well was washed twice with washing buffer containing $0.1 \%$ SDS and $10 \mathrm{mM}$ Tris-EDTA, pH 7.5. Captured aggregates were detected by immunoblotting using the anti-ubiquitin and the TAU C3 antibodies.

In-gel proteasome activity and levels. Upon treatment with vehicle (control, DMSO or water) or the respective drugs, cells were washed twice with PBS and harvested for the in-gel assay as described in Wang et al. ${ }^{9}$ The native gels loaded with $30 \mu \mathrm{g}$ protein/lane, were run at $150 \mathrm{~V}$ for $120 \mathrm{~min}$. The in-gel proteasome activity was detected by incubating the native gel on a rocker for $10 \mathrm{~min}$ at $37^{\circ} \mathrm{C}$ with $15 \mathrm{ml}$ of $300 \mu \mathrm{M}$ Suc-LLVY-AMC followed by exposure to UV light $(360 \mathrm{~nm})$. Gels were photographed with a NIKON Cool Pix 8700 camera with a 3-4219 fluorescent green filter (Peca Products, Inc., Beloit, WI, USA). Proteins on the native gels were transferred $(110 \mathrm{~mA})$ for $2 \mathrm{~h}$ onto PVDF membranes. Immunoblotting was carried out for detection of the 20S and 26S proteasomes with the anti- $\beta 5$ subunit antibody, which reacts with a subunit of the $20 \mathrm{~S}$ core particle, therefore detects $26 \mathrm{~S}$ and $20 \mathrm{~S}$ proteasomes. The antigen was visualized by a chemiluminescent horseradish peroxidase method with the ECL reagent.

Intracellular CAMP. After treatment, media was removed and $500 \mu \mathrm{l}$ of $0.1 \mathrm{~N}$ $\mathrm{HCl}$ were added to each dish followed by incubation for $5 \mathrm{~min}$. Cell lysates were harvested and centrifuged at $600 \times \mathrm{g}$ for $10 \mathrm{~min}$ at room temperature. The supernatant was used directly in the non-acetylated version of the assay. cAMP levels were determined with a non-radioactive assay kit following manufacturer's specifications. Absorbance was measured at $405 \mathrm{~nm}$ with correction at $570 \mathrm{~nm}$, with a PowerWave HT Spectrophotometer (Winooski, VT, USA). CAMP concentration (pmol $/ \mu \mathrm{g}$ protein) for each sample was determined according to the kit's instructions.

Caspase activity assays. Caspase activity assays (for caspases 3,8 and 9) were carried out with caspase colorimetric assay kits from Biovision (Mountain View, CA, USA) following manufacturer's specifications.

Statistical analysis. Statistical significance was estimated using one-way ANOVA (Tukey-Kramer multiple comparison test) with the Instat 2.0, Graphpad Software (San Diego, CA, USA).

\section{Conflict of Interest}

The authors declare no conflict of interest.

Acknowledgements. We thank Dr. L Binder (Northwestern University, Chicago) for the TAU C5 and TAU C3 antibodies. This work was supported by NIH (NS41073 (Specialized Neuroscience Research Programs) to MF-P (head of subproject) from NINDS; AG028847 to MF-P from NIA; NCRR-RR003037 to Hunter College infrastructure from NIGMS/RCMI).

1. Mandelkow E, von BM, Biernat J, Mandelkow EM. Structural principles of tau and the paired helical filaments of Alzheimer's disease. Brain Pathol 2007; 17: 83-89.

2. Gamblin TC, Chen F, Zambrano A, Abraha A, Lagalwar S, Guillozet AL et al. Caspase cleavage of tau: linking amyloid and neurofibrillary tangles in Alzheimer's disease. Proc Natl Acad Sci USA 2003; 100: 10032-10037.

3. Rissman RA, Poon WW, Blurton-Jones M, Oddo S, Torp R, Vitek MP et al. Caspasecleavage of tau is an early event in Alzheimer disease tangle pathology. $J$ Clin Invest 2004; 114: 121-130.

4. de Calignon A, Fox LM, Pitstick R, Carlson GA, Bacskai BJ, Spires-Jones TL et al. Caspase activation precedes and leads to tangles. Nature 2010; 464: 1201-1204.

5. Cotman CW, Poon WW, Rissman RA, Blurton-Jones M. The role of caspase cleavage of tau in Alzheimer disease neuropathology. J Neuropathol Exp Neurol 2005; 64: 104-112. 
6. Upadhya SC, Hegde AN. Role of the ubiquitin proteasome system in Alzheimer's disease. BMC Biochem 2007; 8(Suppl 1): S12.

7. Oddo S. The ubiquitin-proteasome system in Alzheimer's disease. J Cell Mol Med 2008 ; 12: 363-373.

8. Ishii T, Sakurai T, Usami H, Uchida K. Oxidative modification of proteasome: identification of an oxidation-sensitive subunit in $26 \mathrm{~s}$ proteasome. Biochemistry 2005; 44: 13893-13901.

9. Wang Z, Aris VM, Ogburn KD, Soteropoulos P, Figueiredo-Pereira ME. Prostaglandin J2 alters pro-survival and pro-death gene expression patterns and $26 \mathrm{~S}$ proteasome assembly in human neuroblastoma cells. J Biol Chem 2006; 281: 21377-21386.

10. Aiken CT, Kaake RM, Wang X, Huang L. Oxidative stress-mediated regulation of proteasome complexes. Mol Cell Proteomics 2011; 10: R110.

11. Arnaud LT, Myeku N, Figueiredo-Pereira ME. Proteasome-caspase-cathepsin sequence leading to tau pathology induced by prostaglandin J2 in neuronal cells. J Neurochem 2009; 110: 328-342.

12. Groll M, Kim KB, Kairies N, Huber R, Crews CM. Crystal structure of epoxomicin:20S proteasome reveals a molecular basis of a',b'-epoxomicin proteasome inhibitors. J Am Chem Soc 2000; 122: 1237-1238.

13. Qiu JH, Asai A, Chi S, Saito N, Hamada H, Kirino T. Proteasome inhibitors induce cytochrome c-caspase-3-like protease- mediated apoptosis in cultured cortical neurons [In Process Citation]. J Neurosci 2000; 20: 259-265.

14. Goldberg AL. Functions of the proteasome: from protein degradation and immune surveillance to cancer therapy. Biochem Soc Trans 2007; 35: 12-17.

15. Uchida K, Shibata T. 15-Deoxy-Delta(12,14)-prostaglandin J2: an electrophilic trigger of cellular responses. Chem Res Toxicol 2008; 21: 138-144.

16. Monneret G, Li H, Vasilescu J, Rokach J, Powell WS. 15-Deoxy-delta 12,14-prostaglandins D2 and J2 are potent activators of human eosinophils. J Immunol 2002; 168: 3563-3569.

17. Hata AN, Zent R, Breyer MD, Breyer RM. Expression and molecular pharmacology of the mouse CRTH2 receptor. J Pharmacol Exp Ther 2003; 306: 463-470.

18. Silveira MS, Linden R. Neuroprotection by cAMP: Another brick in the wall. Adv Exp Med Biol 2006; 557: 164-176.

19. Miller JP, Shuman DA, Scholten MB, Dimmitt MK, Stewart CM, Khwaja TA et al. Synthesis and biological activity of some 2' derivatives of adenosine 3',5'-cyclic phosphate. Biochemistry 1973; 12: 1010-1016.

20. Moody TW, Ito T, Osefo N, Jensen RT. VIP and PACAP: recent insights into their functions/ roles in physiology and disease from molecular and genetic studies. Curr Opin Endocrinol Diabetes Obes 2011; 18: 61-67.

21. Joo KM, Chung YH, Kim MK, Nam RH, Lee BL, Lee KH et al. Distribution of vasoactive intestinal peptide and pituitary adenylate cyclase-activating polypeptide receptors (VPAC1, VPAC2, and PAC1 receptor) in the rat brain. J Comp Neurol 2004; 476: 388-413.

22. Cheng X, Ji Z, Tsalkova T, Mei F. Epac and PKA: a tale of two intracellular cAMP receptors. Acta Biochim Biophys Sin (Shanghai) 2008; 40: 651-662.

23. de Wit RJ, Hekstra D, Jastorff B, Stec WJ, Baraniak J, Van DR et al. Inhibitory action of certain cyclophosphate derivatives of cAMP on cAMP-dependent protein kinases. Eur $\mathrm{J}$ Biochem 1984; 142: 255-260.

24. Wanker EE, Scherzinger E, Heiser V, Sittler A, Eickhoff H, Lehrach H. Membrane filter assay for detection of amyloid-like polyglutamine-containing protein aggregates. Methods Enzymol 1999; 309: 375-386.

25. Bedford L, Hay D, Devoy A, Paine S, Powe DG, Seth R et al. Depletion of 26S proteasomes in mouse brain neurons causes neurodegeneration and Lewy-like inclusions resembling human pale bodies. J Neurosci 2008; 28: 8189-8198.
26. Tseng BP, Green KN, Chan JL, Blurton-Jones M, LaFerla FM. Abeta inhibits the proteasome and enhances amyloid and tau accumulation. Neurobiol Aging 2008; 29 : 1607-1618.

27. Zhang F, Hu Y, Huang P, Toleman CA, Paterson AJ, Kudlow JE. Proteasome function is regulated by cyclic AMP-dependent protein kinase through phosphorylation of Rpt6. J Biol Chem 2007; 282: 22460-22471.

28. Asai M, Tsukamoto O, Minamino T, Asanuma H, Fujita M, Asano $\mathrm{Y}$ et al. PKA rapidly enhances proteasome assembly and activity in in vivo canine hearts. $J$ Mol Cell Cardiol 2009; 46: 452-462.

29. Nikolaev VO, Gambaryan S, Engelhardt S, Walter U, Lohse MJ. Real-time monitoring of the PDE2 activity of live cells: hormone-stimulated cAMP hydrolysis is faster than hormonestimulated cAMP synthesis. J Biol Chem 2005; 280: 1716-1719.

30. Fouad K, Ghosh M, Vavrek R, Tse AD, Pearse DD. Dose and chemical modification considerations for continuous cyclic AMP analog delivery to the injured CNS. J Neurotrauma 2009; 26: 733-740.

31. Schwede F, Maronde E, Genieser H, Jastorff B. Cyclic nucleotide analogs as biochemical tools and prospective drugs. Pharmacol Ther 2000; 87: 199-226.

32. Kojro E, Postina R, Buro C, Meiringer C, Gehrig-Burger K, Fahrenholz F. The neuropeptide PACAP promotes the alpha-secretase pathway for processing the Alzheimer amyloid precursor protein. FASEB J 2006; 20: 512-514.

33. Sacchetti B, Lorenzini CA, Baldi E, Bucherelli C, Roberto M, Tassoni G et al. Pituitary adenylate cyclase-activating polypeptide hormone (PACAP) at very low dosages improves memory in the rat. Neurobiol Learn Mem 2001; 76: 1-6.

34. Rat D, Schmitt U, Tippmann F, Dewachter I, Theunis C, Wieczerzak E et al. Neuropeptide pituitary adenylate cyclase-activating polypeptide (PACAP) slows down Alzheimer's disease-like pathology in amyloid precursor protein-transgenic mice. FASEB J 2011; 25: 3208-3218.

35. Reglodi D, Kiss P, Lubics A, Tamas A. Review on the protective effects of PACAP in models of neurodegenerative diseases in vitro and in vivo. Curr Pharm Des 2011; 17: 962-972.

36. Keller JN, Hanni KB, Markesbery WR. Impaired proteasome function in Alzheimer's disease. J Neurochem 2000; 75: 436-439.

37. Keller JN, Gee J, Ding Q. The proteasome in brain aging. Ageing Res Rev 2002; 1: 279-293.

38. Piotrowski J, Beal R, Hoffman L, Wilkinson KD, Cohen RE, Pickart CM. Inhibition of the 26 $\mathrm{S}$ proteasome by polyubiquitin chains synthesized to have defined lengths. $\mathrm{J}$ Biol Chem 1997; 272: 23712-23721.

39. Keck S, Nitsch R, Grune T, Ullrich O. Proteasome inhibition by paired helical filament-tau in brains of patients with Alzheimer's disease. J Neurochem 2003; 85: $115-122$.

40. Mosmann T. Rapid colorimetric assay for cellular growth and survival: application to proliferation and cytotoxicity assays. J Immunol Methods 1983; 65: 55-63.

Cell Death and Disease is an open-access journal published by Nature Publishing Group. This work is licensed under the Creative Commons Attribution-NonCommercial-No Derivative Works 3.0 Unported License. To view a copy of this license, visit http://creativecommons.org/licenses/by-nc-nd/3.0/ 